\title{
Effects of soil type and composition of rhizodeposits on rhizosphere priming phenomena
}

\author{
Davidson A. Lloyd ${ }^{\mathrm{a}}$, Karl Ritz ${ }^{\mathrm{a} 1}$, Eric Paterson ${ }^{\mathrm{b}}$, Guy J.D. Kirk ${ }^{\mathrm{a} 2}$ \\ ${ }^{a}$ Cranfield Soil and Agrifood Institute, Cranfield University, Cranfield, Bedford MK43 OAL, UK \\ ${ }^{\mathrm{b}}$ The James Hutton Institute, Craigiebuckler, Aberdeen, AB15 8QH, Scotland, UK
}

\begin{abstract}
Inputs of fresh plant-derived C may stimulate microbially-mediated turnover of soil organic matter (SOM) in the rhizosphere. But studies of such 'priming' effects in artificial systems often produce conflicting results, depending on such variables as rates of substrate addition, substrate composition, whether pure compounds or mixtures of substrates are used, and whether the addition is pulsed or continuous. Studies in planted systems are less common, but also produce apparently conflicting results, and the mechanisms of these effects are poorly understood.
\end{abstract}

To add to the evidence on these matters, we grew a $\mathrm{C} 4$ grass for $61 \mathrm{~d}$ in two contrasting soils an acid sandy soil and a more fertile clay-loam - which had previously only supported C3 vegetation. We measured total soil respiration and its $\mathrm{C}$ isotope composition, and used the latter to partition the respiration between plant- and soil-C sources. We found SOM turnover was enhanced (i.e. positive priming) by plant growth in both soils. In treatments in which the grass was clipped, net growth was greatly diminished, and priming effects were correspondingly weak. In treatments without clipping, net plant growth, total soil respiration and SOM-derived respiration were all much greater. Further, SOM-derived respiration increased over time in parallel with increases in plant growth, but the increase was delayed in the less fertile soil. We conclude the observed priming effects were driven by microbial demand for $\mathrm{N}$, fuelled by deposition of $\mathrm{C}$ substrate from roots and competition with roots for $\mathrm{N}$. The extent of priming depended on soil type and plant growing conditions.

In a further experiment, we simulated rhizodeposition of soluble microbial substrates in the same two soils with near-continuous additions for $19 \mathrm{~d}$ of either C4-labelled sucrose (i.e. a simple single substrate) or a maize root extract (i.e. a relatively diverse substrate), and we measured soil respiration and its $\mathrm{C}$ isotope signature. In the more fertile soil, sucrose induced increasingly positive priming effects over time, whereas the maize root extract produced declining priming effects over time. We suggest this was because $\mathrm{N}$ and other nutrients were provided from the mineralization of this more diverse substrate. In the less-fertile soil, microbial $\mathrm{N}$ demand was probably never satisfied by the combined mineralization from added substrate and soil organic matter. Therefore priming

\footnotetext{
${ }^{1}$ Current address: School of Biosciences, The University of Nottingham, Sutton Bonington Campus, Sutton Bonington, Leicestershire LE12 5RD, UK

${ }^{2}$ Corresponding author: School of Water, Energy \& Environment, Cranfield University, Cranfield, Bedford MK43 0AL, UK. Tel +44 1234758068.

E-mail address: g.kirk@cranfield.ac.uk
} 
effects were approximately constant over time. We conclude that the chemical nature of putative priming compounds can greatly influence priming phenomena.

Keywords: Priming effect, soil organic matter, rhizosphere, C4 grass, stable isotopes

\section{Introduction}

From 10 to $20 \%$ of photosynthetic $\mathrm{C}$ fixed by plants is released into the rhizosphere as rhizodeposits: that is, soluble exudates, insoluble secretions, rhizosphere $\mathrm{C}$ flow and detrital root material (Gregory, 2006; Wichern et al., 2008; Jones et al., 2009). Some of this rhizodeposition is used by microbial communities for respiration and biomass production, and subsequent turnover of the biomass contributes to soil organic matter (SOM) pools. In the process, some part, particularly high-energy compounds present in root exudates, may be used by microbes to accelerate mineralisation of existing SOM through so-called priming effects. Such effects are widely observed, but they are poorly understood (Cheng et al., 2014; Zhu et al., 2014). However, in the context of feedbacks to environmental change, they may be of equal or greater importance to global $\mathrm{C}$ and nutrient cycles as above-ground plant growth.

Priming effects are known to vary with plant type and such variables as canopy photosynthetic rate, plant phenology, root architecture, mycorrhizal symbiosis, and the quality and quantity of root exudates (Dijkstra et al., 2006; Kuzyakov, 2010; Phillips et al., 2012; Shahzad et al., 2015). They also vary with soil type, though this has been less studied (Billings et al., 2010; Kuzyakov, 2010; Paterson and Sim, 2013; Cheng et al., 2014). Important variables are likely to be soil nutrient status, $\mathrm{N}$ availability, soil water relations and toxic phenomena, as these can all influence plant growth rates and microbial activity. Priming effects can be either amplified or diminished by nutrient availability. A key hypothesis to explain this is that plant-derived labile $\mathrm{C}$ benefits rhizosphere microbes, which in turn can mobilize nutrients from soil organic matter, which in turn benefits the plants (Kuzyakov, 2010; Cheng et al., 2014; Murphy et al., 2015). Hence the interactions between plant and soil variables governing priming effects are complex.

In this study we aimed to add to the evidence on the effects of soil type and the nature of rhizodeposits on rhizosphere priming, and to investigate possible mechanisms to explain the effects. We made experiments with two contrasting soils: both relatively nutrient-poor grassland soils, but one more acidic and with organic matter with a much greater $\mathrm{C}: \mathrm{N}$ ratio. We used $\mathrm{C} 4 \mathrm{Kikuyu}$ grass (Pennisetum clandestinum) as a model plant, which we found would grow well in the two soils in comparison with other $\mathrm{C} 4$ grasses. Because our soils contained organic matter derived exclusively from past $\mathrm{C} 3$ vegetation, and the $\mathrm{C}$ isotope signature of $\mathrm{C} 3$ respiration was of the order of $10 \%$ more negative than $\mathrm{C} 4$ respiration, we could use the isotope signature of soil respired $\mathrm{CO}_{2}$ to partition the respiration into plant and soil sources. Further, we used a periodic grass clipping treatment to vary rhizodeposition: clipping was expected to decrease photosynthetic $\mathrm{C}$ fixation, root:shoot partitioning and root exudation. In a parallel experiment with the same two soils, we measured the effect of simulated rhizodeposition with near-continuous additions of mixedcomposition $\mathrm{C} 4$ substrates.

\section{Materials and methods}

\subsection{Soils}

The soils were collected from 0-5 $\mathrm{cm}$ depth at two locations: (1) a surface water gley soil, Brockhurst series, at Temple Balsall, Warwickshire, England (276559N, 420189E), sampled in March 2012 (hereafter referred to as the clay soil); and (2) a brown sand, Cottenham series, at Shuttleworth College, Bedfordshire, England (243867N 514421E), sampled in May 2012 (hereafter referred to as the sandy soil). Both sites were under long-term C3 grasses, the sandy soil with C3 
bracken, and both with no fertilizer applications for at least 5 years. The soils were air-dried and sieved $(<6 \mathrm{~mm})$ after removing recognisable plant fragments. The properties of the sieved soils were (a) clay soil: clay loam texture, $\mathrm{pH}(\mathrm{KCl}) 5.5$, organic $\mathrm{C} 46.2 \mathrm{~g} \mathrm{~kg}^{-1}$, total $\mathrm{N} 4.9 \mathrm{~g} \mathrm{~kg}^{-1}, \mathrm{C}: \mathrm{N}$ ratio 9.4; and (b) sandy soil: loamy sand texture, $\mathrm{pH}(\mathrm{KCl}) 3.8$, organic $\mathrm{C} 64.8 \mathrm{~g} \mathrm{~kg}^{-1}$, total $\mathrm{N} 4.2 \mathrm{~g}$ $\mathrm{kg}^{-1}, \mathrm{C}: \mathrm{N}$ ratio 15.4. The $\mathrm{pH}$ of the sandy soil was raised to 5.0 by adding $4 \mathrm{~g} \mathrm{~kg}^{-1}$ of powdered $\mathrm{CaCO}_{3}$, moistening to field capacity and leaving for over 12 months, by which time all the $\mathrm{CaCO}_{3}$ had reacted with the soil (i.e. there was no residual effect on the $\delta^{13} \mathrm{C}$ of soil respiration).

\subsection{Experiment A: actual rhizodeposition}

\subsubsection{Experimental design}

The experiment was conducted in a glasshouse at Cranfield University, Bedfordshire, UK from May to July 2014. Mean day- and night-time temperatures in the glasshouse during the experiment were $28.5 \pm 0.6$ and $15.0 \pm 0.3^{\circ} \mathrm{C}$, respectively. The experiment consisted of the two soils, planted or not with Kikuyu grass (Pennisetum clandestinum Hochst. ex Chiov, obtained from Barenbrug Holland B.V., Nijmegen, Netherlands) which was either clipped or unclipped. Soil $\mathrm{CO}_{2}$ efflux and its $\delta^{13} \mathrm{C}$ were measured periodically, and destructive harvests were made at the midpoint and end of the experiment to determine plant growth.

Sieved soil $(<6 \mathrm{~mm})$ was moistened to $60 \%$ of water holding capacity and packed into $300 \mathrm{~mm}$ long, $103 \mathrm{~mm}$ internal diameter PVC tubes to $250 \mathrm{~mm}$ depth with 1.5 and $1.4 \mathrm{~kg}$ soil per pot for the clay and sandy soils, respectively. The base of each pot was capped with a fabric mesh to block roots. Soil moisture was maintained at $60 \%$ of water holding capacity throughout the experiment by daily watering to weight. Seeds of Kikuyu grass were sown at a rate of 20 seeds per pot, 2-3 mm below the soil surface in a circular band approximately $30 \mathrm{~mm}$ from the edge of the pots. A single application of $0.16 \mathrm{~g} \mathrm{pot}^{-1}$ of water soluble fertilizer (36-0-12 NPK + trace elements; Vitax, Leicester, UK) was made shortly after germination. A gas sampling chamber made of $100 \mathrm{~mm}$ long, $46 \mathrm{~mm}$ ID PVC pipe was placed over the bare soil in the middle of the pots and pushed down to 3 $\mathrm{cm}$ depth. The top of the chamber was fitted with a PVC cap containing gas-tight inlet and outlet ports with three-way Luer-lock stopcocks.

A total of 20 pots were prepared for each soil. Four replicates from each treatment were destructively sampled at 48 days after planting (DAP) and the remaining pots at 61 DAP. In the clipped treatments, clipping was carried out weekly starting at 31 DAP, and was sufficient to reduce plant height to $3 \mathrm{~cm}$ above the soil. Clippings were retained for analyses. Soil $\mathrm{CO}_{2}$ efflux and its $\delta^{13} \mathrm{C}$ were measured every few days from 21 DAP as described in Section 2.2.2. At harvests, the gas sampling chamber was removed from the pot and any soil adhering to it was removed and added to the bulk soil. In the planted pots, shoots were cut at soil level, placed in paper bags and oven-dried at $100^{\circ} \mathrm{C}$ for $24 \mathrm{~h}$ to determine shoot biomass. The soil and roots were transferred to a large tray and roots were extracted by hand and shaken lightly to remove loosely-attached soil. The roots were then thoroughly washed with deionized water and oven-dried to determine root biomass. A portion of the fresh roots was retained for measuring the $\delta^{13} \mathrm{C}$ of root respiration (Section 2.2.2). Soil samples were analysed within $1 \mathrm{~d}$ of sampling for total $\mathrm{C}$ and $\mathrm{N}$ using an elemental analyser (Elementar Vario EL, Hanau, Germany) and for microbial biomass by fumigation extraction (Vance et al., 1987). Prior to microbial biomass measurements, the soil was re-sieved $(<6 \mathrm{~mm})$ and recognisable plant fragments were removed. This procedure will not capture very fine plant material and loose cells, but this will be a small part of the measured microbial biomass, as is recognised in the wide use of fumigation-extraction in rhizosphere studies. 


\subsubsection{Soil respiration and $\delta^{13} C$ measurements}

For respiration measurements, the gas sampling chamber was connected to a closed loop $(1 / 8$ inch ID BEV A-line tubing) containing a diaphragm pump (Charles Austen DA1 SE1, Byfleet, UK), a column of soda lime to scrub $\mathrm{CO}_{2}$ from the air, and an infrared gas analyser (IRGA; Licor LI-820, Lincoln NE, USA). Air was circulated at approximately $1 \mathrm{~L} \mathrm{~min}^{-1}$ for $2 \mathrm{~min}$, which was sufficient to reduce the chamber $\mathrm{CO}_{2}$ mixing ratio to $<1 \mu \mathrm{mol} \mathrm{mol}^{-1}$. The $\mathrm{CO}_{2}$ scrubber was then bypassed, and the $\mathrm{CO}_{2}$ emitted from the soil surface over the subsequent $15 \mathrm{~min}$ was measured. The soil respiration flux $F_{\mathrm{S}}\left(\mu \mathrm{mol} \mathrm{C} \mathrm{m}^{-2}\right.$ soil s${ }^{-1}$ ) was calculated from the measured rate of change in $\mathrm{CO}_{2}$ concentration in the microcosm headspace in the final 2 min of the post-scrubbing period using the equation

$$
F_{\mathrm{S}}=\frac{\Delta C}{\Delta t} \times \frac{V}{A}
$$

where $\Delta C$ is the change in headspace $\mathrm{CO}_{2}$ concentration ( $\mu$ mol $\mathrm{C} \mathrm{m}^{-3}$ ) over time $\Delta t(\mathrm{~s}), V$ is the headspace volume $\left(\mathrm{m}^{3}\right)$ and $A$ is the surface area of bare soil $\left(\mathrm{m}^{2}\right)$.

Four $5 \mathrm{~cm}^{3}$ air samples were then withdrawn from the chamber headspace with a gas syringe (SGE Europe Ltd, Milton Keynes, UK), and transferred to separate $12 \mathrm{~cm}^{3}$ exetainers (Labco, High Wycombe, UK) capped with gas-tight septa and pre-evacuated and purged with He. The samples were analysed for $\delta^{13} \mathrm{C}$ within $24 \mathrm{~h}$ using an isotope ratio mass spectrometer (IRMS) with the following protocol.

The IRMS was a Sercon 20-22 (Sercon Ltd, Crewe, UK) fitted with an auto-sampler. A cycle of isotope measurements started with a peak centre routine, followed by three injections of reference $\mathrm{CO}_{2}$ gas (99.999\% pure $\mathrm{CO}_{2}$, Research Grade N5.0, BOC, Guildford, UK), and then a sequence of six gas samples was injected with a reference $\mathrm{CO}_{2}$ injection between each sample. Nitrogen, $\mathrm{O}_{2}$ and $\mathrm{N}_{2} \mathrm{O}$ were separated from $\mathrm{CO}_{2}$ in a GC column (Poropak QS, Sigma-Aldrich) and eluted before the $\mathrm{CO}_{2}$. The flow of $\mathrm{He}$ and the $\mathrm{GC}$ column temperature were adjusted to achieve baseline separation of $\mathrm{CO}_{2}$ from the other air constituents. The reference $\mathrm{CO}_{2}$ gas was calibrated against a VPDB secondary standard (c/o SerCon). Carbon isotope ratios relative to VPDB, $\delta^{13} \mathrm{C}(\%)$, were calculated from

$$
\delta^{13} \mathrm{C}=\left[\frac{\left({ }^{13} C /{ }^{12} C\right)_{\text {sample }}}{\left({ }^{13} C /{ }^{12} C\right)_{\mathrm{VPDB}}}-1\right] \times 1000
$$

The precision of $\delta^{13} \mathrm{C}$ values for repeat Exetainer samplings was $\pm 0.2 \%$.

We determined the fraction of the measured respiration derived from the native soil organic matter $\left(f_{\text {som }}\right)$ as follows. From mass balance we have for the component fluxes

$$
F_{\mathrm{S}}=F_{\mathrm{SOM}}+F_{\text {root }}
$$

and

$$
\delta^{13} \mathrm{C}_{\mathrm{S}} F_{\mathrm{S}}=\delta^{13} \mathrm{C}_{\mathrm{SOM}} F_{\mathrm{SOM}}+\delta^{13} \mathrm{C}_{\text {root }} F_{\text {root }}
$$

where subscripts S, SOM and root indicate total, SOM-derived and root-derived respiration, respectively. Also

$$
F_{\text {SOM }}=f_{\text {SOM }} F_{\mathrm{S}}
$$


Combining Equations (3)-(5) and rearranging gives

$$
f_{\text {SOM }}=\frac{\delta^{13} \mathrm{C}_{\mathrm{S}}-\delta^{13} \mathrm{C}_{\text {root }}}{\delta^{13} \mathrm{C}_{\mathrm{SOM}}-\delta^{13} \mathrm{C}_{\text {root }}}
$$

In Equation (6), $\delta^{13} \mathrm{C}_{\mathrm{SOM}}$ values were determined from $\delta^{13} \mathrm{C}_{\mathrm{S}}$ for the unplanted control soils, and $\delta^{13} \mathrm{C}_{\text {root }}$ values were determined with freshly sampled plant roots, with and without adhering soil, placed in $12 \mathrm{~cm}^{3}$ vials and incubated for $20 \mathrm{~min}$, after which samples were analysed for $\delta^{13} \mathrm{C}$ (after Midwood et al., 2006).

\subsection{Experiment B: simulated rhizodeposition}

\subsubsection{Experimental design}

Following Paterson et al. (2007), samples of the soils ( $<2 \mathrm{~mm}$ sieved) were moistened to $65 \%$ of water holding capacity and packed into semi-circular sections of PVC pipe (120 mm length, 46 $\mathrm{mm}$ internal diameter) to dry bulk densities of 0.7 and $0.8 \mathrm{~g} \mathrm{~cm}^{-3}$ for the clay and sandy soils, respectively, giving $100 \mathrm{~cm}^{3}$ of soil in each microcosm. For each soil, 12 such 'microcosms' were prepared to allow three treatments (two C4 substrates and a control) with four replicates. The microcosms were placed in individual 1-L Kilner jars with 1-mm pore diameter mesh lids to allow gas exchange, and pre-incubated in the dark at $20^{\circ} \mathrm{C}$ and $80 \%$ humidity for $16 \mathrm{~d}$ before treatments were applied, maintaining constant soil moisture contents by watering to the original weight daily.

The substrate treatments were maize root extract (Section 2.3.3) or sugarcane sucrose (Billington's Fairtrade Light Brown Sugar), each applied at 0.35 and $0.2 \mathrm{mg} \mathrm{C} \mathrm{g}^{-1}$ soil d $^{-1}$ for the clay and sandy soils, respectively. These rates of addition were in proportion to rates of grass growth measured in the two soils (Lloyd, 2015). The rates are equivalent to approx. $2 \mathrm{~kg} \mathrm{C} \mathrm{m}^{-2}$ in $100 \mathrm{~d}\left[=\operatorname{rate}\left(\mathrm{mg} \mathrm{C} \mathrm{g}^{-1}\right.\right.$ soil d $\left.{ }^{-1}\right) \times$ bulk density $\left(\mathrm{g} \mathrm{cm}^{-3}\right) \times \operatorname{depth}(10 \mathrm{~cm}) \times$ time $(100 \mathrm{~d}) \times$ unit conversion], which is comparable to the annual net primary productivity of a fertile grassland in southern, lowland Britain. The treatments were applied daily in $1 \mathrm{~cm}^{3}$ of solution (which was the minimum moisture loss per microcosm in $1 \mathrm{~d}$ ), sprayed uniformly over the soil with a syringe. Additional moisture as required to maintain constant soil weight was applied as deionised water mixed with the treatment solution. Soil respiration and $\delta^{13} \mathrm{C}$ were measured every few days as described in Section 2.3.2, and measurements were continued until $19 \mathrm{~d}$ following the initial treatment applications.

\subsubsection{Soil respiration and $\delta^{13} \mathrm{C}$ measurements}

To measure respiration rates and their $\delta^{13} \mathrm{C}$, the mesh lids on the Kilner jars containing the microcosms were replaced with gas-tight lids fitted with inlet and outlet ports and Luer-lock valves. These were connected to a closed loop containing a pump, $\mathrm{CO}_{2}$ scrubber and IRGA as in Section 2.2.2. Air was circulated at a flow rate of approximately $1 \mathrm{~L} \mathrm{~min}^{-1}$ and the $\mathrm{CO}_{2}$ scrubbing continued until the $\mathrm{CO}_{2}$ mixing ratio was $<10 \mu \mathrm{mol} \mathrm{mol}^{-1}$. The $\mathrm{CO}_{2}$ scrubber was then bypassed by switching the Luer-lock valves connecting it to the main loop, and subsequent $\mathrm{CO}_{2}$ emission from the soil was monitored for a further $2.5 \mathrm{~h}$. The soil respiration flux $F_{\mathrm{S}}$ was calculated from the measured rate of change in $\mathrm{CO}_{2}$ concentration in the microcosm headspace in the final $2 \mathrm{~min}$ of this period using equation (1).

At the end of the incubation period, three $5 \mathrm{~cm}^{3}$ air samples were withdrawn from the headspace using a $10 \mathrm{~cm}^{3}$ gas syringe (SGE Europe Ltd, Milton Keynes, UK) via a Luer-lock valve. The samples were injected into separate $12 \mathrm{~cm}^{3}$ Exetainers (Labco, High Wycombe, UK) capped with gas-tight septa and pre-evacuated and purged with He. The samples were analysed for $\delta^{13} \mathrm{C}$ within $24 \mathrm{~h}$ using the protocol described in Section 2.2.2. 
We determined the fraction of the measured respiration derived from the native soil organic matter $\left(f_{\text {SOM }}\right)$ with the equation $(c . f$. equation 6$)$

$$
f_{\text {SOM }}=\frac{\delta^{13} \mathrm{C}_{\mathrm{S}}-\delta^{13} \mathrm{C}_{\text {substrate }}}{\delta^{13} \mathrm{C}_{\mathrm{SOM}}-\delta^{13} \mathrm{C}_{\text {substrate }}}
$$

In equation (8), $\delta^{13} \mathrm{C}_{\mathrm{SOM}}$ values were determined from $\delta^{13} \mathrm{C}_{\mathrm{S}}$ for the control soils, un-amended with substrate (averaged over the experimental period), and $\delta^{13} \mathrm{C}_{\text {substrate }}$ values were determined in samples of the substrates (freeze-dried maize root extract and granular sugarcane) on a Flash EA 1112 Elemental Analyser connected via a Conflo III to a Delta Plus XP IRMS (all Thermo Finnigan, Bremen, Germany) at The James Hutton Institute. The values were $-12.20 \%$ and -11.52 $\%_{0}( \pm 0.1 \%)$ for maize root extract and sugarcane, respectively.

\subsubsection{Maize root extract}

Maize (Zea mays L. Marai F1 hybrid early variety, Unwins GroSure, Huntingdon, UK) was grown in a 3:1 mixture of compost and horticultural sand in $1 \mathrm{~L}$ pots (4 seeds per pot). The plants were watered daily and fertilized weekly with an all-purpose soluble fertilizer, and harvested after 8 weeks. Shoots were removed at their base and the roots washed free of the potting mixture using deionised water. The roots were liquidized in a stainless-steel juicer (BNIB 700W-2011, Amazon), and the resulting mash was centrifuged at $8000 \mathrm{~g}$ for $10 \mathrm{~min}$, filtered (Whatman GF/B glass microfiber filters), and the filtrate freeze dried and stored in a desiccator until used. The extract was analysed for total $\mathrm{C}$ and $\mathrm{N}$ contents using an elemental analyser (Elementar Vario EL, Hanau, Germany), and for sugar and other contents by high performance liquid chromatography (Agilent 1260 Infinity HPLC-ELSD, Santa Clara, CA, USA). This showed the extract had a C:N ratio of 34 and contained $121 \mathrm{mg} \mathrm{g}^{-1}$ glucose, $87 \mathrm{mg} \mathrm{g}^{-1}$ fructose and a mixture of other unidentified carbohydrates and amino compounds. We consider the root extract to represent, albeit imperfectly, the soluble root exudate and cell lysate components of rhizodeposition.

\subsection{Statistical analyses}

Statistical analyses were made using Statistica version 12.5 (Statsoft Inc.,Tulsa, OK, USA). After confirming the individual data were normally distributed, with homogeneous variance, repeated measures ANOVA was used to assess treatment effects on total soil $\mathrm{CO}_{2}$ efflux and its $\delta^{13} \mathrm{C}$, and two-way ANOVA was used to determine the significance of clipping effects in the two soils. Differences between means were analysed using post hoc Fisher least significant difference.

\section{Results}

\subsection{Experiment $A$}

\subsubsection{Plant biomass production}

There were large and significant $(P<0.001)$ differences in plant growth between the soils and between the clipping treatments (Fig. 1). In the unclipped treatments, growth was 12 -fold greater in the clay soil at 48 DAP, but the sandy soil had somewhat caught up by 61 DAP when the difference was only 2-fold. In both soils, clipping significantly suppressed net growth (i.e. biomass at harvest plus biomass of clippings). At 48 DAP the ratios of unclipped to clipped growth were 2 and 15 in the sandy and clay soils, respectively, but 20 and 7, respectively, at 61 DAP. Total biomass production at both times increased in the order sandy clipped $<$ clay clipped $<$ sandy unclipped $<$ clay unclipped. There were also differences $(P<0.001)$ in the effects of clipping on root growth and root:shoot ratios. At 48 DAP, clipping had not affected the, albeit poor, root growth in the sandy soil, but in the clay soil it had reduced root growth 17 -fold compared with the unclipped 
treatment. Whereas at 61 DAP, root growth was 67 - and 25 -fold smaller in the clipped sandy and clay soils, respectively, the root biomass having decreased by $35 \%$ between 48 and 61 DAP in the sandy soil though it increased 4-fold in the clay soil. In both soils the root to shoot ratio in the clipped treatments decreased significantly over time whereas it increased significantly in the unclipped treatments. Though Kikuyu grass can be rhizomatous and stoloniferous, we did not observe any rhizomes or stolons, only roots.

\subsubsection{Soil respiration and its $\delta^{13} C$}

Total soil respiration flux $\left(F_{\mathrm{S}}\right)$ was relatively constant over time in the unplanted control soils and there were no differences $(P<0.001)$ between the two soils (Fig. 2a, b). The presence of plants significantly increased $F_{\mathrm{S}}$ in both soils, though more slowly and to a smaller extent in the sandy soil. In the unclipped treatments, the increase by 48 DAP was six-times basal respiration in the clay soil but only two-times basal in the sandy soil; in the clay soil, $F_{\mathrm{S}}$ did not increase further beyond 48 DAP whereas in the sandy soil it continued to increase reaching 10 times basal respiration at 61 DAP.

Clipping commenced at $31 \mathrm{DAP}$ and greatly decreased $F_{\mathrm{S}}$ in both soils. In the clipped sandy soil, $F_{\mathrm{S}}$ was not significantly different from basal soil respiration at any time. In the clay soil clipping also suppressed $F_{\mathrm{S}}$ compared with no clipping, but it remained above basal respiration though the differences were only significant $(P<0.001)$ at 27 and 48 DAP. The effect of clipping was immediate. In the clay soil, $F_{\mathrm{S}}$ decreased by $30 \%$ within $1 \mathrm{~d}$ of the start of clipping (31 DAP).

There were significant differences in $\delta^{13} \mathrm{C}$ between the soils and treatments (Fig. 2c, d). As expected, planting with $\mathrm{C} 4 \mathrm{Kikuyu}$ grass caused $\delta^{13} \mathrm{C}$ of total soil respiration to be less negative to an extent depending on the rate of plant growth. Hence the shifts increased in the order sandy clipped < clay clipped < sandy unclipped < clay unclipped. The $\delta^{13} \mathrm{C}$ values of root respiration measured on freshly harvested soil-free roots were $-13.5 \pm 0.7 \%$ and $-12.8 \pm 0.9 \%$ in the sandy and clay soils, respectively. There were no significant differences between clipped and unclipped plants. The values measured on roots with adhering rhizosphere soil were $-14.4 \pm 0.6 \%$ and $-13.1 \pm$ $0.6 \%$ in the sandy and clay soils, respectively.

\subsubsection{Rhizosphere priming effects}

Figures $3 \mathrm{a}-\mathrm{d}$ show the soil $\mathrm{CO}_{2}$ efflux partitioned according to SOM- and root-derived components using the data in Fig. 2. In the unclipped treatments, SOM turnover was stimulated in both soils and the effect increased with plant growth. In the clay soil, SOM turnover increased 2fold at 48 DAP but only negligibly in the sandy soil. But at 61 DAP the increases were comparable in the two soils, roughly 2-fold. In clipped treatments, there was no significant stimulation of SOM turnover in either soil. The plant contribution to the total soil $\mathrm{CO}_{2}$ efflux increased gradually with time in the unclipped treatments in both soils. The pattern of increase was different in the two soils with clay unclipped plants making an earlier significant contribution, consistent with the trends in plant growth (Fig. 1).

The unclipped plants produced positive priming in both soils, and the effects increased with plant growth (Fig. 3c, d). Overall the clay soil produced greater priming effects, however the greatest priming effect occurred in the sandy soil at $61 \mathrm{DAP}$, with an additional $9.76 \pm 1.66 \mu \mathrm{mol} \mathrm{C}$ $\mathrm{m}^{-2} \mathrm{~s}^{-1}$. Clipping produced no or only weak priming effects in both soils. Four of the nine measurements made in the sandy soil produced negative priming effects, while all measurements from clipping treatments in the clay soil showed positive priming effects. But none of these effects were statistically significant. 
The size of the microbial biomass was more than six times greater in the clay soil control than the sandy soil control, viz. $2235 \pm 58$ versus $316 \pm 75 \mu \mathrm{g} \mathrm{C} \mathrm{g}^{-1}$ respectively. There were no differences $(P>0.05)$ in microbial biomass between the planted and unplanted soils (data not shown).

\subsection{Experiment $B$}

Basal soil respiration rates in both soils stabilised after the pre-incubation period at $0.16 \pm 0.06$

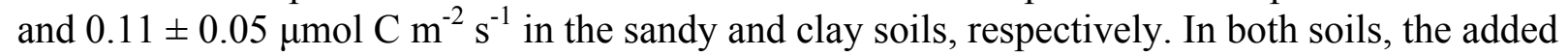
substrates both produced several-fold increases in total soil respiration rates (Fig. 4a, b). After the initial period, the increase was greater with sucrose than maize extract, particularly in the clay soil, though the amounts of $\mathrm{C}$ added per unit mass of soil were the same for both substrates. From the second day after treatment (DAT) $F_{\mathrm{S}}$ in sucrose-treated clay soil was significantly greater than that in maize-treated clay soil and increased with time. At the end of the experiment the respiration flux was 2.4-fold greater with sucrose than maize extract in the clay soil. The increases in respiration fluxes in the clay soil were up to 32 and $23 \%$ of the addition of sucrose and maize extract (equivalent to 5.4 and $3.1 \mu \mathrm{mol} \mathrm{C} \mathrm{m}^{-2} \mathrm{~s}^{-1}$ ), respectively.

The $\delta^{13} \mathrm{C}_{\mathrm{S}}$ values for respiration in the control soils were stable over the experiment. The values were $-18.7 \pm 0.2$ and $-19.8 \pm 0.1 \%$ in the sandy and clay soils, respectively. Addition of the C4 substrates resulted in less negative $\delta^{13} \mathrm{C}_{\mathrm{S}}$ values (i.e. relatively more enriched in ${ }^{13} \mathrm{C}$ ), as expected, by up to $8 \%$ over time.

In both soils the effects of both substrates on $F_{\text {SOM }}$ were mostly to increase SOM-derived respiration compared with the controls, indicating positive priming effects (Fig. 4c, d). Sucrose produced significantly greater priming than maize root extract over time in both soils, but particularly in the clay soil. There were similar patterns of change in $F_{\text {SOM }}$ in the soils over the first few days, with a rapid $(<1 \mathrm{~d})$ increase and then little change. But from $6 \mathrm{~d}$ the soils behaved very differently. In the sandy soil, with both substrates SOM-derived respiration remained roughly constant or declined gradually but remained greater than in the control (i.e. positive priming). But in the clay soil, with the maize extract, SOM-derived respiration decreased sharply over time and was less than in the control soil (i.e. negative priming) after $12 \mathrm{~d}$; whereas with sucrose, it increased over time until the final measurements.

\section{Discussion}

\subsection{Actual rhizodeposition}

In Experiment A, in general, total soil respiration increased over time in the planted treatments as the plants grew, and the contributions of plant-derived $\mathrm{C}$ to the total respiration increased, especially in the unclipped treatments and especially in the clay soil. The better plant growth in the clay soil presumably allowed greater net photosynthetic $\mathrm{C}$ fixation and consequently greater rhizodeposition. Consequently SOM-derived respiration increased in parallel with the increase in direct plant-derived respiration, and was generally comparable to it.

In both soils, clipping caused reduced net plant growth as well as net leaf area for photosynthesis, and also reduced root biomass and, by inference, rhizodeposition. This was particularly so in the less fertile sandy soil, where plant growth was in any case much weaker, and the contribution of plant-derived $C$ to total soil respiration became negligible. Diminished net $C$ fixation and root growth with clipping are consistent with previous studies summarised by Ferraro and Oesterheld (2002). Diminished root exudation and plant-derived soil respiration with clipping are also consistent with previous work (Shahzad et al., 2012; Schmitt et al., 2013), including in Kikuyu grass (Roper et al., 2013). 
Total soil respiration was several-fold smaller in clipped than unclipped treatments in both soils. Over the first day following the first clipping (31 DAP), total respiration decreased by 17 and $4 \%$ in the clay and sandy soils, respectively, and by the second day it had decreased by 48 and $55 \%$ in the two soils, respectively. It is reported that clipping can induce an initial flush of root exudation (Hamilton et al., 2008). However, if this occurred in our system, the effect was only transient and was over within $1 \mathrm{~d}$. The dominant effect was decreased net photosynthetic $\mathrm{C}$ fixation and, consequently, decreased rhizodeposition.

Rates of SOM mineralization were far greater in the unclipped planted treatments than in the unplanted controls in both soils, indicating positive priming effects. We consider these to be real priming effects representing increased mineralization of SOM, as opposed to apparent priming, where the increase in soil respiration is from increased turnover of microbial biomass with a $\delta^{13} \mathrm{C}$ equivalent to that of SOM (Kuzyakov, 2010). This is evident from the increasing trajectory of priming with plant growth, whereas apparent priming is a short-term process that declines as the SOM-derived component of the active microbial biomass declines as it is replaced by plant-derived $\mathrm{C}$ (i.e. resulting in a declining $F_{\text {SOM }}$ over time following an initial flush). We posit our observed priming effects were real and reflected enhanced SOM mineralization induced by rhizodeposition.

\subsection{Simulated rhizodeposition}

In Experiment B, our most striking results were the differences between the soils, and, in the clay soil, the differences between the substrates in eliciting priming effects. In the clay soil, sucrose induced increasingly positive priming effects over time, whereas the maize root extract produced declining priming effects over time. In the sandy soil, priming effects were approximately constant over time. The clay soil is inherently more fertile than the sandy soil: it is less acid, its organic matter has a smaller $\mathrm{C}: \mathrm{N}$ ratio (9.4 versus 15.4$)$ and it has a greater baseline microbial biomass. Consistent with this, grass growth rates in the clay soil in Experiment A were roughly twice those in the sandy soil.

\subsubsection{Interactions between $C$ and $N$ mineralization}

Based on the assumption that priming effects are driven by microbial demand for nutrients other than $\mathrm{C}$, our tentative explanation for the soil differences is that the returns of $\mathrm{N}$ that microbes get from mineralizing soil organic matter in the clay soil are greater than those in the less-fertile sandy soil with its much larger $\mathrm{C}: \mathrm{N}$ ratio. Therefore, with sucrose, priming effects were greater and increased over time. Note that the return of $\mathrm{N}$ may be greater than indicated by the SOM C:N ratio because priming may target N-rich compounds (Rousk et al., 2016). By contrast, with maize root extract, which itself contains nutrients in addition to $\mathrm{C}(\mathrm{C}: \mathrm{N}$ ratio 34 , whereas the sucrose contained no $\mathrm{N}$ ), the cumulative addition of nutrients over time reduced microbial SOM mining to obtain nutrients, as also found by Murphy et al. (2015). Hence the priming effect in the maize-treated clay soil fell over time. By contrast, in the less-fertile sandy soil, microbial demand for $\mathrm{N}$ and other nutrients was not satisfied by priming, or by the nutrient content of the maize extract, so priming effects were smaller and did not decline to the same extent with the cumulative addition of maize nutrients.

We suggest that this result is consistent with the relative availability of $\mathrm{C}$ and $\mathrm{N}$ sources being a key determinant of microbial SOM mineralization activity. That is, in the fertile clay soil, the intrinsic $\mathrm{N}$-supply capacity in combination with $\mathrm{N}$ supplied in maize extract was sufficient to meet microbial N-demand and therefore, to lessen energy-demanding SOM mineralization (Paterson, 2009). That this effect only became evident after 1 week of additions may be because, although $\mathrm{C}$ is progressively lost through microbial respiration, $\mathrm{N}$ is better conserved, particularly in systems where there is no plant uptake. This contrasts with the increased positive priming with sucrose 
additions, where microbial N-demand would have increased over time as a consequence of increased growth and activity. The sandy soil received a smaller maize extract addition based on its poorer fertility and smaller expected rhizodeposition under field conditions. Therefore, the continued priming with maize extract in this soil likely reflects the smaller $\mathrm{N}$ input and smaller supply from SOM mineralization, such that microbial N demand was not met. Simple, generally monotonous, substrates are frequently used in soil priming-effect studies, but here we demonstrate that the nature of the substrates can have a significant effect on priming phenomena. This observation is also of consequence given that the composition of root exudates is known to vary widely between growth stages and species (Badri and Vivanco, 2009; Pausch et al., 2013; MelladoVazquez et al., 2016), and hence different plants may have inherently different priming effects.

\subsubsection{Effects of transport limitations}

A potential artefact of Experiment B is the extent of differences in dispersal of the applied substrates into the soils. The initial dispersal of substrate will have been by mass flow with the applied solution. Mass flow may have been a little faster in the sandy soil than the clay, because of greater infiltration rates, resulting in greater substrate dispersal. We suppose subsequent further dispersal by diffusion will have been less important, it being much slower. Likewise we suppose differences in penetration between the substrates due to differences in sorption by the soil solid will have been small, because sorption will have been slower than mass flow. How will such differences have influenced our results? If the substrate is more dispersed into the soil, and so is less concentrated in the zone affected, then to the extent that rates of respiration and priming are concentration-dependent, this will have influenced the results. However we consider this to be part and parcel of the differences between the soils. In the rhizosphere, dispersion of rhizodeposits away from the root will likewise differ with differences in soil transport properties.

\subsubsection{Isotope fractionation effects}

There is some uncertainty in the values of the $\delta^{13} \mathrm{C}$ of soil respiration in Experiment $\mathrm{B}$. The values measured in the control soils in Experiment B were significantly less negative than those in the control soils in Experiment A. Following Nickerson and Risk (2009) and Ohlsson (2010), we suppose this is due to isotopic fractionation in transient-state diffusion of respired $\mathrm{CO}_{2}$ through the soil to the purged microcosm chambers, which is expected to be greater in Experiment $\mathrm{B}$ for reasons discussed in Appendix A. In calculations given in Appendix A, we show that the apparent error in $\delta^{13} \mathrm{C}$ values will cause the size of the priming effect to be under-estimated, but the trends across the treatments and over time are unchanged.

\subsection{Plant and soil processes driving priming effects}

We hypothesize that the priming effects we observed were driven by microbial demand for $\mathrm{N}$ fuelled by rhizodeposition of $\mathrm{C}$ substrate and competition with plants for $\mathrm{N}$. Our reasoning is as follows. The results show a gradual increase in priming as plant biomass and rhizodeposition increased. Both soils were low in nutrients and, in the unclipped treatments, the plants increased their root:shoot ratios over time, presumably to increase their nutrient capture. The increased root growth will have been accompanied by increased rhizodeposition and consequently increased priming of SOM mineralization. As the plants grew, demand for soil nutrients will have increased, in competition with rhizosphere microbes. So increased $\mathrm{C}$ substrate supply in the rhizosphere would have been accompanied by increased competition for non- $\mathrm{C}$ nutrients.

With the exception of the initial small fertilizer application to support plant establishment, all the nutrients required for plant growth were acquired from the soil. Taking a conservative mean plant $\mathrm{N}$ content of $20 \mathrm{mg} \mathrm{g}^{-1}$ dry matter, $\mathrm{N}$ uptake by $61 \mathrm{DAP}$ was 35, 172, 709 and $1239 \mathrm{mg} \mathrm{N}$ pot $^{-}$ ${ }^{1}$ in the clipped and unclipped sandy and clay soils, respectively. The application of $\mathrm{N}$ fertilizer was 
$160 \mathrm{mg} \mathrm{N}_{\text {pot }}{ }^{-1}$, so this was exceeded in all but the clipped sandy soil. The plants therefore largely relied on soil $\mathrm{N}$ for the bulk of their $\mathrm{N}$, certainly in the unclipped treatments, which is where the rhizosphere priming effects were most evident.

The differences in priming between the soils support the hypothesis that priming was driven by $\mathrm{N}$ demand. Plant establishment was faster in the clay soil due to the more-fertile conditions. Once the plants were established, at around 30 DAP, plant-derived respiration $\left(F_{\text {root }}\right)$ initially exceeded SOM-derived respiration $\left(F_{\mathrm{SOM}}\right)$ in the clay soil, but later they were comparable. This pattern is consistent with initial plant and microbial $\mathrm{N}$ demand being met by the basal soil $\mathrm{N}$ supply from basal rates of SOM mineralization, but later demand required enhanced mineralization. Whereas in the sandy soil, $R_{\text {root }}$ never exceeded $F_{\mathrm{SOM}}$, consistent with a greater deficit in soil nutrient supply. Once the plants were established in the sandy soil, priming rates caught up with those in the clay soil and by 61 DAP actually exceeded them.

The soil differences in Experiment $A$ are also consistent with the differences we found in Experiment B in unplanted microcosms of the same soils. We found, in the clay soil, addition of sucrose induced a steadily increasing priming effect over time, whereas with addition of a root extract containing a mixture of $\mathrm{C}$ and $\mathrm{N}$ compounds, the priming effect declined over time as added $\mathrm{N}$ and other nutrients accumulated. In the sandy soil, there were also positive priming effects, but they were relatively constant over time and there were no differences between the substrates in the magnitude of priming effects. Therefore, we could attribute the soil and substrate differences to differences in native soil nutrient supply and interactions between priming and nutrient supply, as was the case for the planted soils.

\section{Conclusions}

Firstly, the presence of plants is not in itself necessarily sufficient to stimulate SOM turnover and priming effects. Plants must develop a certain productive capacity before these processes can set in. Secondly, priming effects tend to increase over the course of plant growth as (a) rates of photosynthesis and rhizodeposition increase, (b) plant and microbial competition for $\mathrm{N}$ and other nutrients in the rhizosphere increase, and (c) rhizodeposition provides sufficient energy for the microbes to obtain nutrients from SOM mineralization. Thirdly, soil type, growing conditions and management all influence the above processes, and hence influence the rate and intensity of rhizosphere priming effects. Fourthly, experiments simulating rhizodeposition with simple, single substrates are likely to be misleading.

Acknowledgments

This work was supported by the Commonwealth Scholarship Commission (Grant number DMCS-2011-95) and the Royal Society/Wolfson Foundation (Grant number WL080021/Kirk).

\section{Appendix A. Supplementary material}

Supplementary material related to this article can be found at XXXX.

\section{References}

Badri, D.V, Vivanco, J.M., 2009. Regulation and function of root exudates. Plant, Cell \& Environment 32, 666-681.

Billings, S.A., Lichter, J., Ziegler, S.E., Hungate, B.A., Richter, D.B., 2010. A call to investigate drivers of soil organic matter retention vs. mineralization in a high $\mathrm{CO}_{2}$ world. Soil Biology and Biochemistry 42, 665-668. 
Cheng, W., Parton, W.J., Gonzalez-Meler, M.A., Phillips, R., Asao, S., McNickle, G.G., Brzostek, E., Jastrow, J.D., 2014. Synthesis and modeling perspectives of rhizosphere priming. New Phytologist 201, 31-44.

Dijkstra, F.A., Cheng, W.X., Johnson, D.W., 2006. Plant biomass influences priming effects on soil organic matter decomposition in two differently managed soils. Soil Biology and Biochemistry $39,2519-2526$.

Ferraro, D.O., Oesterheld, M., 2002. Effect of defoliation on grass growth. A quantitative review. Oikos 98, 125-133.

Gregory, P.J., 2006. Roots, rhizosphere and soil: the route to a better understanding of soil science? European Journal of Soil Science 57, 2-12.

Hamilton III, E.W., Frank, D.A., Hinchey, P.M., Murray, T.R., 2008. Defoliation induces root exudation and triggers positive rhizospheric feedbacks in a temperate grassland. Soil Biology and Biochemistry 40, 2865-2873.

Jones, D.L., Nguyen, C., Finlay, R.D., 2009. Carbon flow in the rhizosphere: carbon trading at the soil-root interface. Plant and Soil 321, 5-33.

Kuzyakov, Y., 2010. Priming effects: interactions between living and dead organic matter. Soil Biology and Biochemistry 42, 1363-1371.

Lloyd, D.A., 2015. Effects of rhizosphere priming and microbial functions on soil carbon turnover. $\mathrm{PhD}$ thesis, Cranfield University.

Mellado-Vazquez, P.G., Lange, M., Bachmann, D., Gockele, A., Karlowsky, S., Milcu, A., Piel, C., Roscher, C., Roy, J., Gleixner, G., 2016. Plant diversity generates enhanced soil microbial access to recently photosynthesized carbon in the rhizosphere. Soil Biology and Biochemistry $94,122-132$.

Midwood, A.J., Gebbing, T., Wendler, R., Sommerkorn, M., Hunt, J.E., Millard, P., 2006. Collection and storage of $\mathrm{CO}_{2}$ for ${ }^{13} \mathrm{C}$ analysis: an application to separate soil $\mathrm{CO}_{2}$ efflux into root- and soil-derived components. Rapid Communications in Mass Spectrometry 20, 33793384.

Murphy, C.J., Baggs, E.M., Morley, N., Wall, D.P., Paterson, E., 2015. Rhizosphere priming can promote mobilisation of N-rich compounds from soil organic matter. Soil Biology and Biochemistry 81, 236-243.

Nickerson, N., Risk, D., 2009. A numerical evaluation of chamber methodologies used in measuring the $\delta^{13} \mathrm{C}$ of soil respiration. Rapid Communications in Mass Spectrometry 23, 28022810.

Ohlsson, K.E.A., 2010. Reduction of bias in static closed chamber measurement of $\delta^{13} \mathrm{C}$ in soil $\mathrm{CO}_{2}$ efflux. Rapid Communications in Mass Spectrometry 24, 180-184.

Paterson, E., Gebbing, T., Abel, C., Sim, A., Telfer, G., 2007. Rhizodeposition shapes rhizosphere microbial community structure in organic soil. New Phytologist 173, 600-610.

Paterson, E., Sim, A., 2013. Soil-specific response functions of organic matter mineralization to the availability of labile carbon. Global Change Biology 19, 1562-1571.

Pausch, J., Zhu, B., Kuzyakov, Y. Cheng, W., 2013. Plant inter-species effects on rhizosphere priming of soil organic matter decomposition. Soil Biology and Biochemistry 57, 91-99. 
Phillips, R.P., Meier, I.C., Bernhardt, E.S., Grandy, A.S., Wickings, K., Finzi, A.C., 2012. Roots and fungi accelerate carbon and nitrogen cycling in forests exposed to elevated $\mathrm{CO}_{2}$. Ecology Letters 15, 1042-1049.

Roper, M.M., Fillery, I.R.P., Jongepier, R., Sanford, P., Macdonald, L.M., Sanderman, J., Baldock, J.A., 2013. Allocation into soil organic matter fractions of ${ }^{14} \mathrm{C}$ captured photosynthesis via photosynthesis by two perrenial grass pastures. Soil Research 51, 748-759.

Rousk, K., Michelsen, A., Rousk, J. 2016. Microbial control of soil organic matter mineralization responses to labile carbon in subarctic climate change treatments. Global Change Biology doi: 10.1111/gcb.13296.

Schmitt, A., Pausch, J., Kuzyakov, Y., 2013. Effect of clipping and shading on C allocation and fluxes in soil under ryegrass and alfalfa estimated by ${ }^{14} \mathrm{C}$ labelling. Applied Soil Ecology 64, $228-236$.

Shahzad, T., Chenu, C., Repinçay, C., Mougin, C., Ollier, J.L., Fontaine, S., 2012. Plant clipping decelerates the mineralization of recalcitrant soil organic matter under multiple grassland species. Soil Biology and Biochemistry 51, 73-80.

Shahzad, T., Chenu, C., Genet, P., Barot, S., Perveen, N., Mougin, C., Fontaine, S., 2015. Contribution of exudates, arbuscular mycorrhizal fungi and litter depositions to the rhizosphere priming effect induced by grassland species. Soil Biology and Biochemistry 80, 146-155.

Vance, E.D., Brookes, P.C., Jenkinson, D.S., 1987. An extraction method for measuring soil microbial biomass C. Soil Biology and Biochemistry 19, 703-707.

Wichern, F. Eberhardta, E., Mayerb, J., Joergensena, G.G., Müller, T., 2008. Nitrogen rhizodeposition in agricultural crops: Methods, estimates and future prospects. Soil Biology and Biochemistry 40, 30-48.

Zhu, B., Gutknecht, J.L.M., Herman, D.J., Keck, D.C., Firestone, M.K., Cheng, W., 2014. Rhizosphere priming effects on soil carbon and nitrogen mineralization. Soil Biology and Biochemistry 76, 183-192. 


\section{Appendix A: Supplementary material}

\section{Isotope fractionation during $\delta^{13} \mathrm{C}$ measurements}

There is some uncertainty in the values of the $\delta^{13} \mathrm{C}$ of soil respiration in Experiment $\mathrm{B}$. The values measured in the control soils in Experiment B were approx. 8 \%o more positive than those in Experiment A. We suppose this is due to isotopic fractionation in the transient-state diffusion of respired $\mathrm{CO}_{2}$ through the soil to the microcosm chambers, as discussed by Nickerson and Risk (2009) and Ohlsson (2010). In systems using purged chambers, such as ours, this can produce a positive $\delta^{13} \mathrm{C}$ bias of up to $15 \%$ (Nickerson and Risk, 2009). Following reasoning given below, the effect is expected to be greater in Experiment $\mathrm{B}$ because of the larger ratio of chamber volume to soil surface area (18 versus $8 \mathrm{~cm})$ and smaller soil depth $(\leq 4.6$ versus $30 \mathrm{~cm})$ and resulting smaller $\mathrm{CO}_{2}$ flux (approx. 10-fold smaller in both soils).

The fractionation arises because ${ }^{12} \mathrm{CO}_{2}$ diffuses slightly faster than the heavier ${ }^{13} \mathrm{CO}_{2}$ (ratio of diffusion coefficients, $D\left({ }^{12} \mathrm{CO}_{2}\right) / D\left({ }^{13} \mathrm{CO}_{2}\right)=1.0044$, i.e. a difference of $4.4 \%$ o). Therefore, at steady state, $\mathrm{CO}_{2}$ in the soil air is isotopically heavier than respired $\mathrm{CO}_{2}$ by roughly $4.4 \%$, and so the $\mathrm{CO}_{2}$ entering the purged chamber in the initial stages is isotopically heavy and there is a positive bias in the measured $\delta^{13} \mathrm{C}_{\mathrm{S}}$ values of approximately $4.4 \%$. As $\mathrm{CO}_{2}$ accumulates in the chamber, a second effect comes into play, which is that, once the chamber $\mathrm{CO}_{2}$ concentration reaches or exceeds the ambient atmospheric concentration, the gradient through the soil - and hence the diffusive flux - declines. This 'chamber feedback' happens more rapidly for ${ }^{12} \mathrm{CO}_{2}$ because of its greater diffusion coefficient. Hence, the chamber ${ }^{13} \mathrm{C} /{ }^{12} \mathrm{C}$ ratio falls less rapidly, also resulting in a positive bias in $\delta^{13} \mathrm{C}_{\mathrm{S}}$ estimates (Nickerson and Risk, 2009). The bias increases with the time required for the $\mathrm{CO}_{2}$ concentration gradient through the soil to reach zero as $\mathrm{CO}_{2}$ accumulates in the chamber, i.e. it varies in inverse relation to $F_{\mathrm{S}}$.

We have tested the effect of the bias by recalculating the priming effects in Experiment $\mathrm{B}$ in two ways. First, by using $\delta^{13} \mathrm{C}_{\mathrm{SOM}}$ values from the $\delta^{13} \mathrm{C}_{\mathrm{S}}$ values for the control soils in Experiment $\mathrm{A}$, and adjusting the measured $\delta^{13} \mathrm{C}_{\mathrm{S}}$ values by the difference between the $\delta^{13} \mathrm{C}_{\mathrm{S}}$ values in the Experiments A and B controls. Second, based on our reasoning that the bias decreases as the respiration flux increases, we calculated $\delta^{13} \mathrm{C}_{\mathrm{S}}$ values with the bias adjusted in inverse proportion to the respiration flux, such that the correction is equal to the difference between the values in the Experiments A and B controls when the flux equals the Experiment B control value, and is zero when the flux equals the Experiment A control value. The true correction is somewhere between these end points. Note there is no diffusive fractionation in the measurements of $\delta^{13} \mathrm{C}_{\text {substrate, }}$ which was obtained by complete combustion of the solid substrate. The results are shown in Figs S1a (fixed correction) and S1b (variable correction). The results show the magnitudes of the estimated priming effects are greater (by up to $50 \%$ with the fixed correction), but the main trends across the treatments and over time are unchanged (compare with Figs 4c and 4d). 


\section{Figure captions}

Fig. 1 Root, shoot and total biomass in the different treatments at (a) 48 days after planting (DAP) and (b) 61 DAP (Experiment A). Clippings are included in the shoot and total values. Values are means $(n=4) \pm$ standard error of mean.

Fig. 2 (a), (b) Soil respiration rates and (c), (d) $\delta^{13} \mathrm{C}$ of soil respiration in planted and unplanted sandy and clay soils, with and without clipping. The $\delta^{13} \mathrm{C}$ of root respiration was $-13.5 \pm 0.7 \%$ in sandy soil and $-12.8 \pm 0.9 \%$ in clay soil. Clipping was done at 31, 38, 49 and 58 DAP. Values are means $(n=4) \pm$ standard error of mean.

Fig. 3 Partitioning of soil respiration between SOM-derived and plant-derived sources in the two soils (a), (b) unclipped and (c), (d) clipped, and (e), (f) the calculated extent of priming in the two soils unclipped and clipped. Values are means $(n=4) \pm$ standard error of mean.

Fig. 4 Effects of near continuous additions of substrates on (a), (b) total and (c), (d) SOM-derived soil respiration rates over time (Experiment B). Values are means $(n=4) \pm$ one standard error of the mean.

Fig. S1. Revised priming effects in Experiment B after allowing for diffusive isotope fractionation due to chamber feedback. (a) $\delta^{13} \mathrm{C}_{\mathrm{S}}$ and $\delta^{13} \mathrm{C}_{\mathrm{SOM}}$ values used in Fig. 4 corrected by difference between values measured in the Experiments A and B controls. (b) $\delta^{13} \mathrm{C}_{\mathrm{SOM}}$ values corrected as in (a) but $\delta^{13} \mathrm{C}_{\mathrm{S}}$ values corrected as a function of the respiration flux (details in text). $\mathrm{SS}=$ sandy soil, $\mathrm{CS}=$ clay soil. 

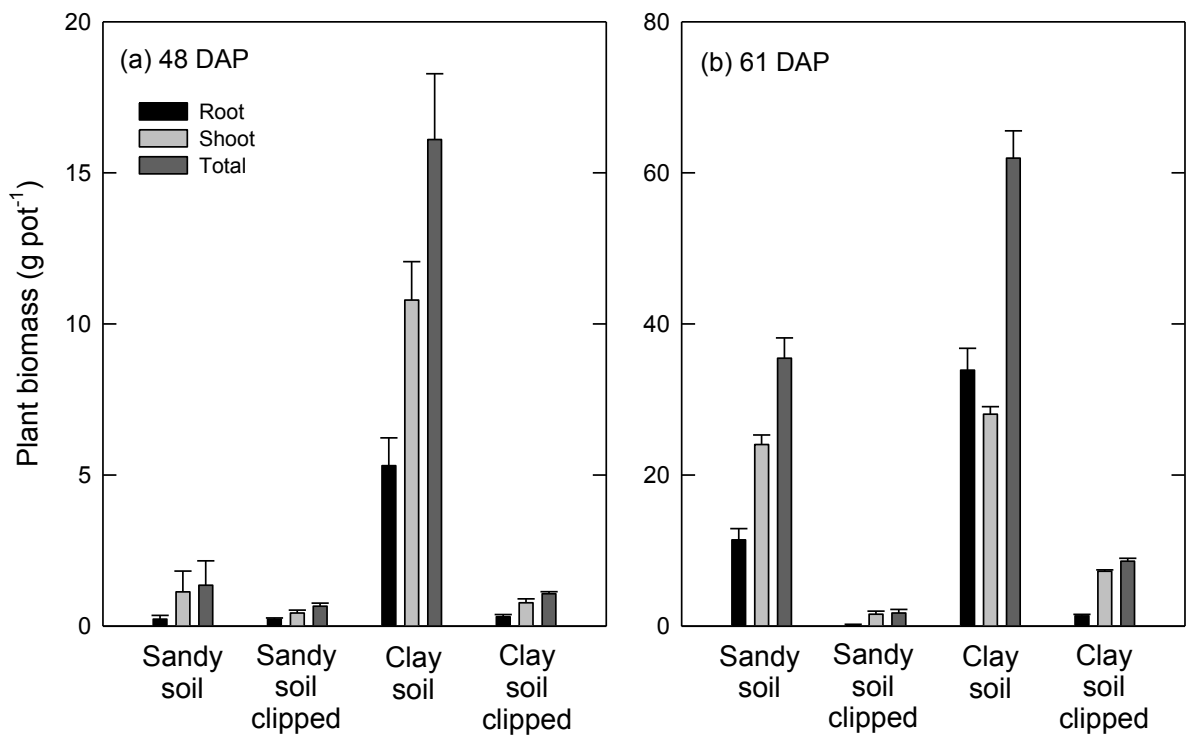

Fig. 1 Root, shoot and total biomass in the different treatments at (a) 48 days after planting (DAP) and (b) 61 DAP (Experiment A). Clippings are included in the shoot and total values. Values are means $(n=4) \pm$ standard error of mean. 

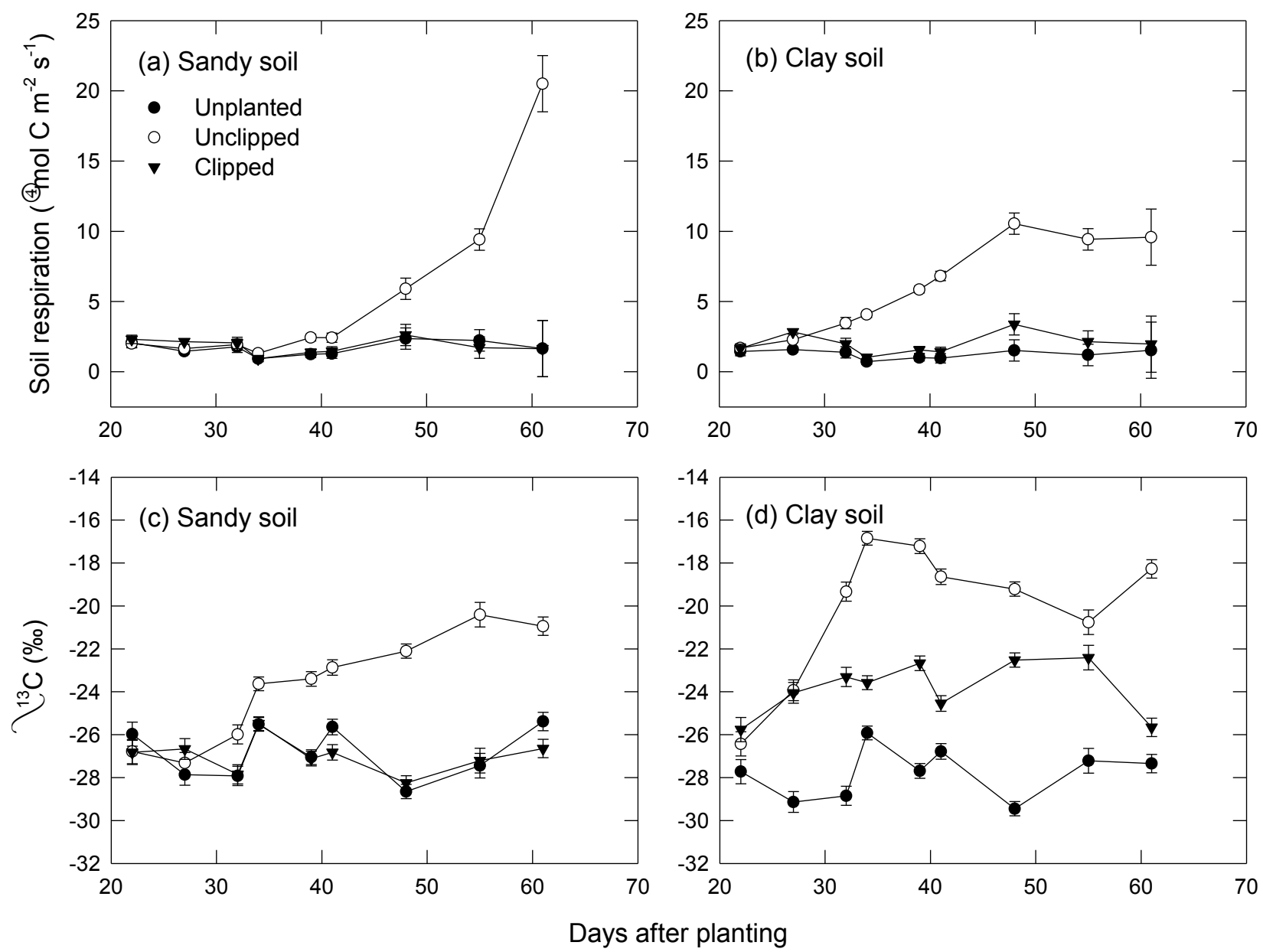

Fig. 2 (a), (b) Soil respiration rates and (c), (d) $\delta^{13} \mathrm{C}$ of soil respiration in planted and unplanted sandy and clay soils, with and without clipping. The $\delta^{13} \mathrm{C}$ of root respiration was $-13.5 \pm 0.7 \%$ in sandy soil and $-12.8 \pm 0.9 \%$ in clay soil. Clipping was done at 31, 38, 49 and 58 DAP. Values are means $(n=4) \pm$ standard error of mean. 

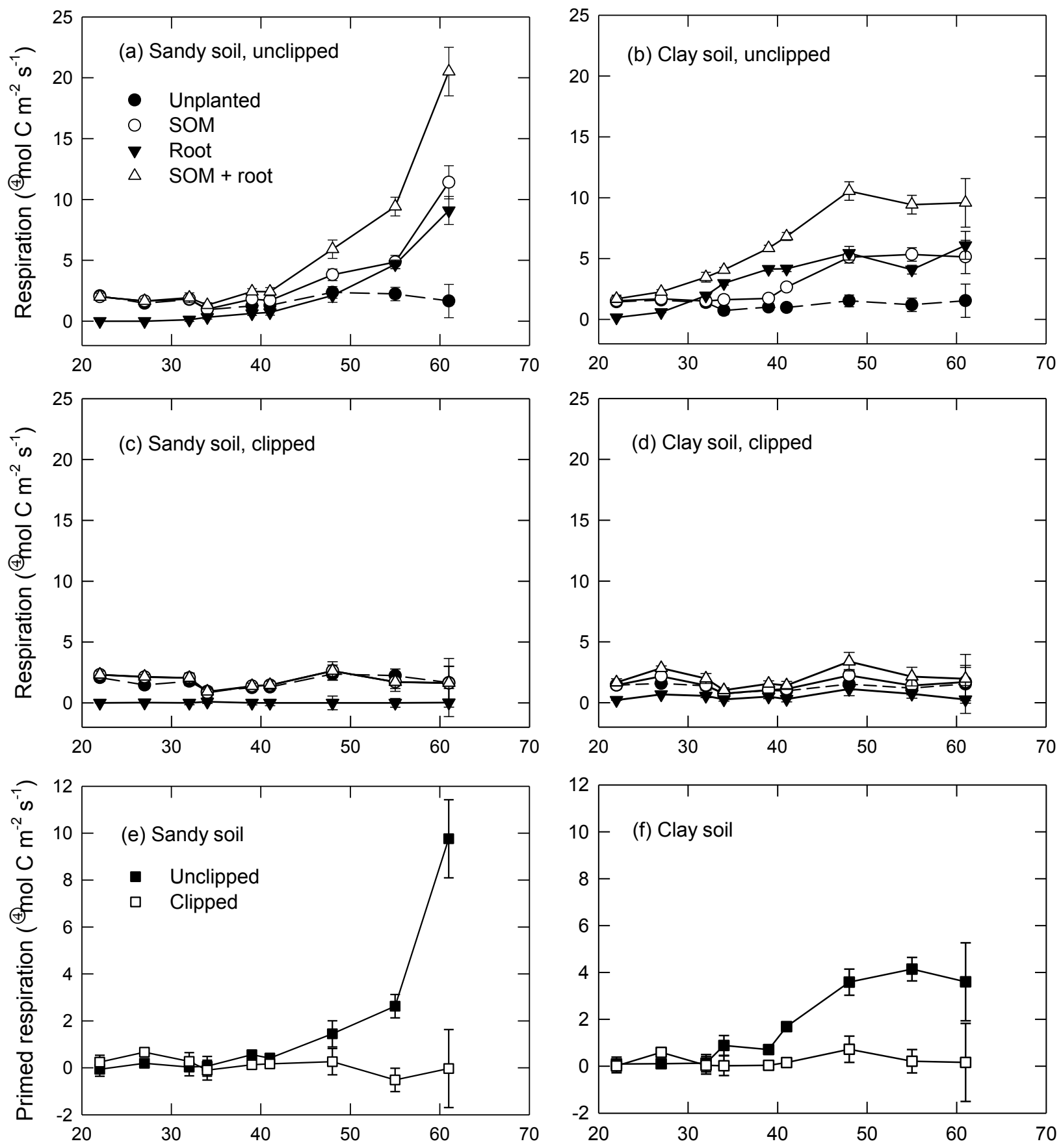

Days after planting

Fig. 3 Partitioning of soil respiration between SOM-derived and plant-derived sources in the two soils (a), (b) unclipped and (c), (d) clipped, and (e), (f) the calculated extent of priming in the two soils unclipped and clipped. Values are means $(n=4) \pm$ standard error of mean. 

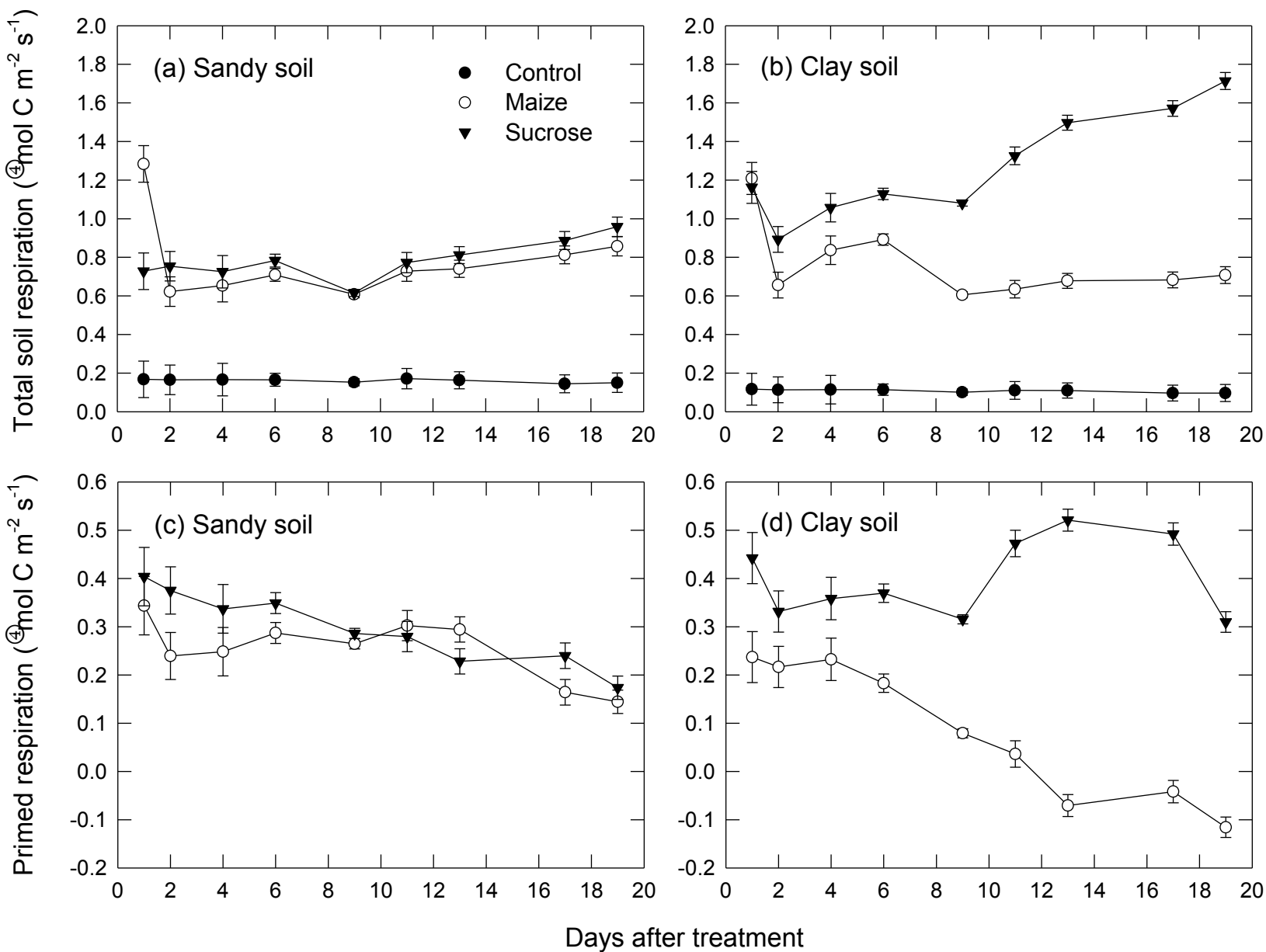

Fig. 4 Effects of near continuous additions of substrates on (a), (b) total and (c), (d) SOM-derived soil respiration rates over time (Experiment B). Values are means $(n=4) \pm$ one standard error of the mean. 
(a) Fixed correction

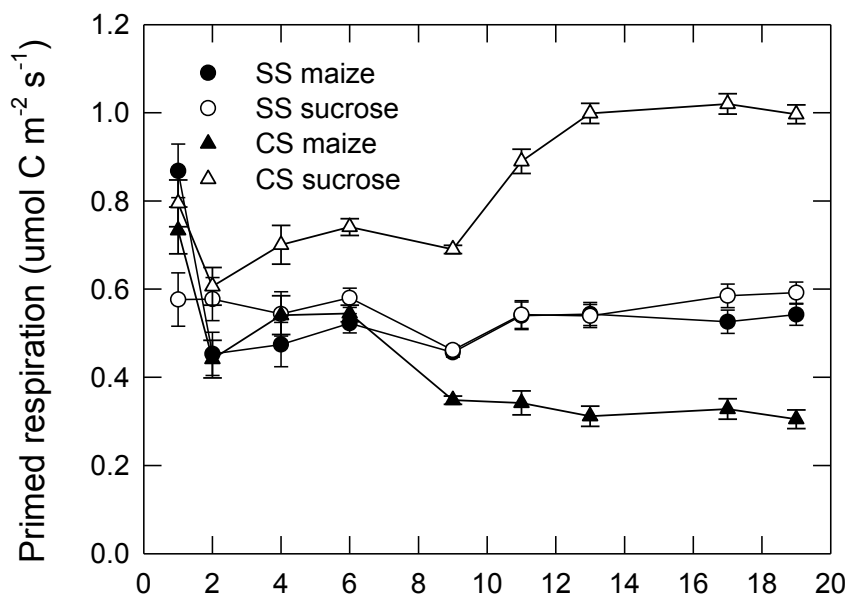

(b) Variable correction

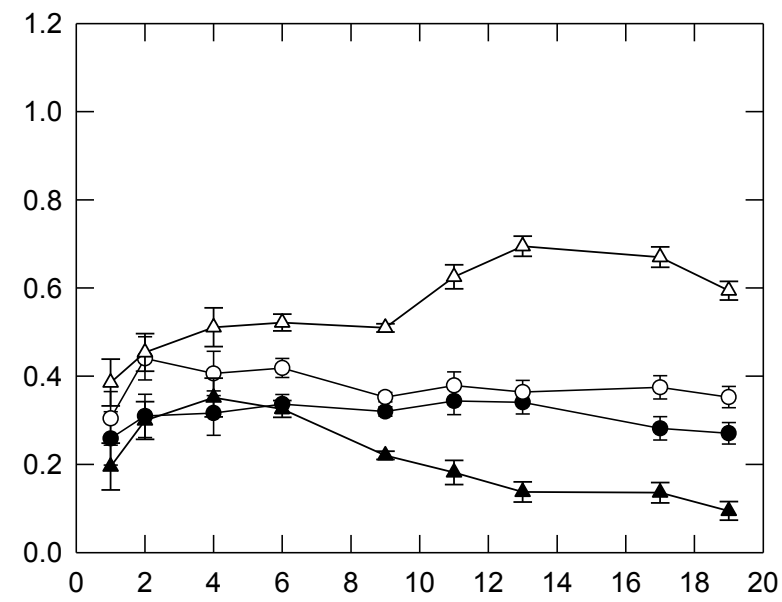

Days after treatment

Fig. S1. Revised priming effects in Experiment B after allowing for diffusive isotope fractionation due to chamber feedback. (a) $\delta^{13} \mathrm{C}_{\mathrm{S}}$ and $\delta^{13} \mathrm{C}_{\mathrm{SOM}}$ values used in Fig. 4 corrected by difference between values measured in the Experiments A and B controls. (b) $\delta^{13} \mathrm{C}_{\mathrm{SOM}}$ values corrected as in (a) but $\delta^{13} \mathrm{C}_{\mathrm{S}}$ values corrected as a function of the respiration flux (details in text). $\mathrm{SS}=$ sandy soil, $\mathrm{CS}=$ clay soil. 